\title{
Intermittent SBAS (ISBAS) InSAR with COSMO-SkyMed X-band high resolution SAR data for landslide inventory mapping in Piana degli Albanesi (Italy)
}

\author{
Francesca Cigna*a ${ }^{\mathrm{a}}$, Alessandro Novellino ${ }^{\mathrm{b}}$, Colm J. Jordan ${ }^{\mathrm{a}}$, Andrew Sowter ${ }^{\mathrm{c}}$, \\ Massimo Ramondini ${ }^{\mathrm{d}}$, Domenico Calcaterra ${ }^{\mathrm{b}}$ \\ ${ }^{\mathrm{a} B r i t i s h}$ Geological Survey, Natural Environment Research Council, Keyworth, UK; ${ }^{\mathrm{b}}$ Dept. of Earth \\ Sciences, Environment and Resources, Federico II University of Naples, Naples, Italy; ${ }^{\mathrm{c}}$ Nottingham \\ Geospatial Institute, University of Nottingham, Nottingham, UK; ${ }^{d}$ Dept. of Civil Architectural and \\ Environmental Engineering, Federico II University of Naples, Naples, Italy
}

\begin{abstract}
In the context of recent advances in InSAR processing techniques to retrieve higher persistent scatterer and coherent target densities over unfavourable land cover classes, this study tests the Intermittent Small Baseline Subset (ISBAS) approach to update the landslide inventory around the town of Piana degli Albanesi (Italy), an area where only $2 \%$ of the land appears suitable to generate radar scatterers based on a pre-survey feasibility assessment. ISBAS processing of 38 ascending mode and 36 descending mode COSMO-SkyMed StripMap HIMAGE SAR scenes at 3m resolution allows identification of $\sim 726,000$ and $\sim 893,000$ coherent and intermittently coherent pixels for the ascending and descending data stacks respectively. Observed improvements in the number of ISBAS solutions for the ascending mode are greater than 40 times compared to the conventional SBAS approach, not only for urban and rocky terrains, but also rural and vegetated land covers. Line of sight ground motion rates range between -6.4 and $+5.5 \mathrm{~mm} / \mathrm{yr}$ in $2008-2011$, although the majority of the processed area shows general stability, with average rates of $-0.6 \mathrm{~mm} / \mathrm{yr}$ in the ascending and $-0.1 \mathrm{~mm} / \mathrm{yr}$ in the descending mode results. Interpretation of the ISBAS deformation rates, integrated with targeted field surveys and aerial photo-interpretation, provides a new and more complete picture of landslide distribution, state of activity and intensity in the test area, and allows depiction of very slow and extremely slow landslide processes even in areas difficult to access, with unprecedented coverage of results.
\end{abstract}

Keywords: InSAR, SBAS, ISBAS, ground motion, intermittent coherence, COSMO-SkyMed, landslide inventory

\section{INTRODUCTION}

A number of Interferometric Synthetic Aperture Radar (InSAR) processing approaches to estimate ground motion have been developed since the $1990 \mathrm{~s}^{1-7}$, and many successful applications carried out over recent years to prove the worth of these techniques to support landslide identification, delineation, assessment of state of activity and monitoring ${ }^{8-16}$. Obtaining InSAR results is, however, particularly challenging across non-urban land covers, such as vegetated terrain, rural regions, hilly and mountainous areas, where landslides generally occur but only a few persistent radar reflectors or coherent pixels can be identified ${ }^{17-19}$. Recent developments in InSAR processing techniques have been aimed at improving the coverage of results, in both urban and non-urban land covers. The SqueeSAR ${ }^{\mathrm{TM}}$ approach $^{20}$ and the Intermittent Small Baseline Subset (ISBAS) technique ${ }^{21}$ are examples of such efforts of the InSAR community, and they are proving capable of greatly increasing the coverage of InSAR results by including distributed scatterers and intermittently coherent pixels, respectively, in their processing solutions. These new techniques have been successfully applied to the study of land motions in areas of natural and anthropogenic geohazards ${ }^{22-24}$.

In this context of InSAR recent advances, this study is focused on a test area in north-western Sicily (Italy), which is affected by landsliding. The area includes the town of Piana degli Albanesi and namesake artificial lake, and the hydroelectric station and minor basin of Guadalami; the latter water bodies both along the Belice River (Figure 1a). According to the Italian Landslide Inventory produced by the Institute for Environmental Protection and Research in

* fcigna@bgs.ac.uk; phone +44 115936 3551; fax +44 1159363446 
2007, a large portion of this area is affected by mass movement processes and the landslide index (i.e. ratio between landslide affected areas and total area, based on $1 \mathrm{~km}$ by $1 \mathrm{~km}$ cells) reaches values over $20 \%$ in some of its sectors to the west and east of the lake, though these statistics are renown to largely underestimate the actual hazard scenario ${ }^{25}$.

Only $\sim 2 \%$ of this region shows good potential for persistent scatterer InSAR applications, mainly in built-up areas and where man-made structures are present. This picture is based on a pre-survey feasibility study and analysis of land covers and their suitability to provide radar scatterers, carried out using the feasibility methodology discussed in ${ }^{17}$.

Landslide-affected slopes in this area are mainly concentrated across rural and semi-vegetated terrain, hence unfavourable land covers, where C- and X-band multi-interferogram InSAR is less likely to succeed. In order to overcome land cover constraints for InSAR applications in non-urban terrain, ground motions in Piana degli Albanesi were therefore analysed by exploiting the ISBAS technique. Intermittently coherent pixels are considered during the analysis, and the coverage of InSAR results is thereby extended to rural, woodland, grassland and agricultural terrains. ISBAS outputs are combined with analysis of ancillary data, including geological, geomorphological and pre-existing landslide inventory maps, and on site surveys for an independent validation of landslide ground motion directions, state of activity and typology.

\subsection{Pre-processing of COSMO-SkyMed imagery}

Input data for this study consist of two stacks of X-band high resolution SAR images acquired by the Dual-Use (Civilian and Defence) end-to-end Earth Observation System named as COnstellation of small Satellites for Mediterranean basin Observation (COSMO-SkyMed) of the Italian Space Agency and the Ministry of Defence. 38 ascending and 36 descending mode StripMap HIMAGE 3m resolution SAR images were used. These cover the region of interest between November 2008 and October 2011, with $\sim 40^{\circ}$ look angle at the centre of the scene, and nominal revisiting time of 16 days.

After precise co-registration to single masters, subsets of the full scenes were selected for both ascending and descending modes, centered at $13.27^{\circ} \mathrm{E}$ and $37.97^{\circ} \mathrm{N}$, to the west of Piana degli Albanesi Lake. The scenes were then multi-looked using a factor of 5 in both azimuth and range to reduce phase noise, thus obtaining $15 \mathrm{~m}$ resolution pixels. To minimize temporal and spatial decorrelation, differential interferograms were generated for small baseline SAR pairs only, these identified by maximum normal baselines of 500m and maximum temporal separation of 2 years, which resulted in 306 interferograms for the ascending and 298 for the descending mode. The subtraction of initial topographic components was performed using a 5m DEM derived using topographic maps at 1:5,000 scale, published in 1990-1994 and distributed by the Regional Cartographic Center.

\subsection{Intermittent SBAS (ISBAS) analysis}

The ascending and descending mode stacks of interferograms were analysed to select intermittently coherent pixels, following the processing approach described in ${ }^{21}$, which in turn builds upon the low-pass SBAS method described by ${ }^{3}$. Coherent pixels were identified by using a coherence threshold of 0.4 to discriminate high from low coherence pixels. A minimum number of 160 and 140 coherent interferograms per pixel was also employed as further threshold to limit the subsequent unwrapping only to pixels for which the best 160 ascending mode interferograms (or 140 for the descending mode) showed an average coherence greater than 0.4 . These thresholds allowed, for each mode, coverage of around $90 \%$ of the region of interest with ground motion results, in terms of either coherent or intermittently coherent pixels.

Further steps of the processing followed the conventional low-pass SBAS approach ${ }^{3}$, with the exception that both coherent and intermittently coherent pixels were processed. This means that in each interferogram, the sparse network of pixels considered coherent or intermittently coherent was unwrapped, by masking out any pixel resulting either rejected throughout the full stack of interferograms, or only in a subset of the latter, due to its intermittent nature.

The location used as reference and to which all ISBAS solutions were referred, was set within the urban fabric of Santa Cristina Gela, to the east of the lake (see Figure 1a). Linear velocities and their standard errors, improved heights and respective errors, as well as average temporal coherence and minimum number of coherent interferograms, and time series of ground motion were generated for both interferogram stacks, in ascending and descending mode. 

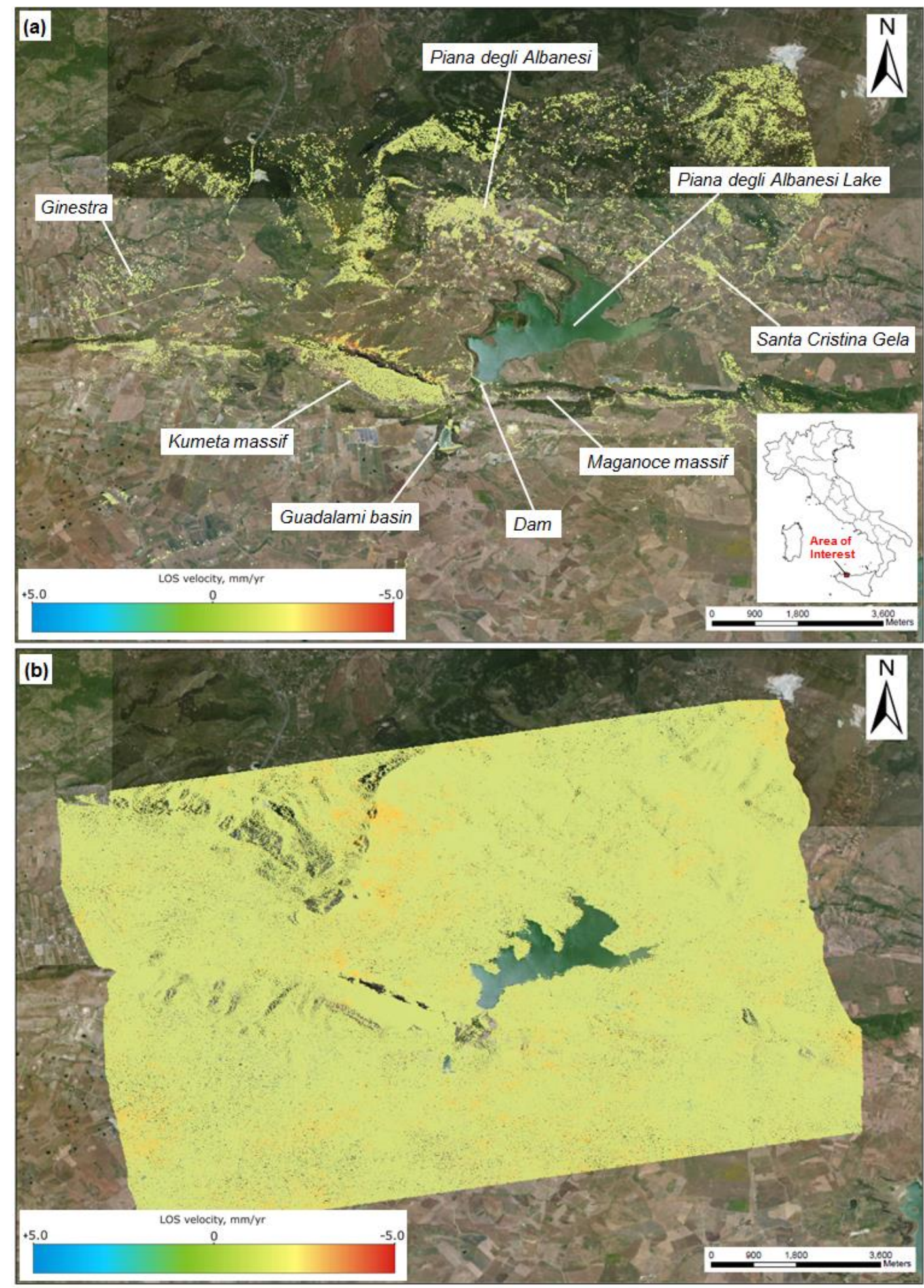

Figure 1: Annual ground motion rates for the area of Piana degli Albanesi (Italy), obtained from the (a) SBAS and (b) ISBAS processing of COSMO-SkyMed StripMap HIMAGE ascending mode data acquired between 2008 and 2011. Motion velocities are saturated to $\pm 5.0 \mathrm{~mm} / \mathrm{yr}$. SBAS and ISBAS results are overlapped onto World Imagery [Source: Esri, DigitalGlobe, GeoEye, i-cubed, Earthstar Geographics, CNES/Airbus DS, USDA, USGS, AEX, Getmapping, Aerogrid, IGN, IGP, swisstopo, and the GIS User Community]. 


\section{ISBAS RESULTS AND DISCUSSION}

\subsection{Coverage and estimated ground motion velocity}

Over 726,000 coherent and intermittently coherent pixels were identified based on the processing of the ascending data, of which $\sim 710,000$ are intermittently coherent, thus representing an increase of more than 40 times the conventional SBAS solution, which encompasses $\sim 16,000$ coherent pixels. The average density of ISBAS results in ascending mode across the processed subset reaches 6,000 pixels $/ \mathrm{km}^{2}$ compared to $\sim 140$ pixels $/ \mathrm{km}^{2}$ for the SBAS solution (Figure $1 \mathrm{a}-\mathrm{b}$ ). A similar scenario was revealed by the processing results for the descending dataset, which allowed identification of over 893,000 coherent and intermittently coherent pixels, for an average density greater than 5,200 pixels $/ \mathrm{km}^{2}$.

SBAS solutions are mainly concentrated in areas dominated by stable scatterers, where urban settlements and linear structures (both road infrastructure and the dam) are present, as well as across areas of debris and rocky terrain, for instance onto the Kumeta massif (Figure 1a). Processing of intermittently coherent areas extends the coverage of results to almost the entire region of interest (Figure 1b), with the exception of radar layover and shadow areas in the northwestern and central portions of the processed subset, and in the steep valley between Kumeta and Maganoce massifs, and water bodies of the Piana degli Albanesi Lake and the Guadalami basin.

Minimum and maximum observed annual velocities along the satellite Line Of Sight (LOS) range between -5.8 and +4.3 $\mathrm{mm} / \mathrm{yr}$ in the ISBAS ascending mode results, and between -6.4 and $+5.5 \mathrm{~mm} / \mathrm{yr}$ in the descending mode results. Nonetheless, in both cases the majority of the processed area shows general stability, with average rates of $-0.6 \mathrm{~mm} / \mathrm{yr}$ in the ascending and $-0.1 \mathrm{~mm} / \mathrm{yr}$ in the descending mode results, and most ISBAS pixels move at rates within the range $\pm 1.5 \mathrm{~mm} / \mathrm{yr}$, the latter usually considered as the stability threshold.

\subsection{Landslide mapping with ISBAS and field-surveying}

Multi-temporal COSMO-SkyMed ISBAS results were combined with ancillary data, including geological, geomorphological and pre-existing landslide inventory maps. On site surveys were also used for independent validation of landslide ground motion directions, state of activity and typology (Figure 2). A summary of the findings of this analysis are reported below, although the detailed discussion of these is beyond the scope of this paper.

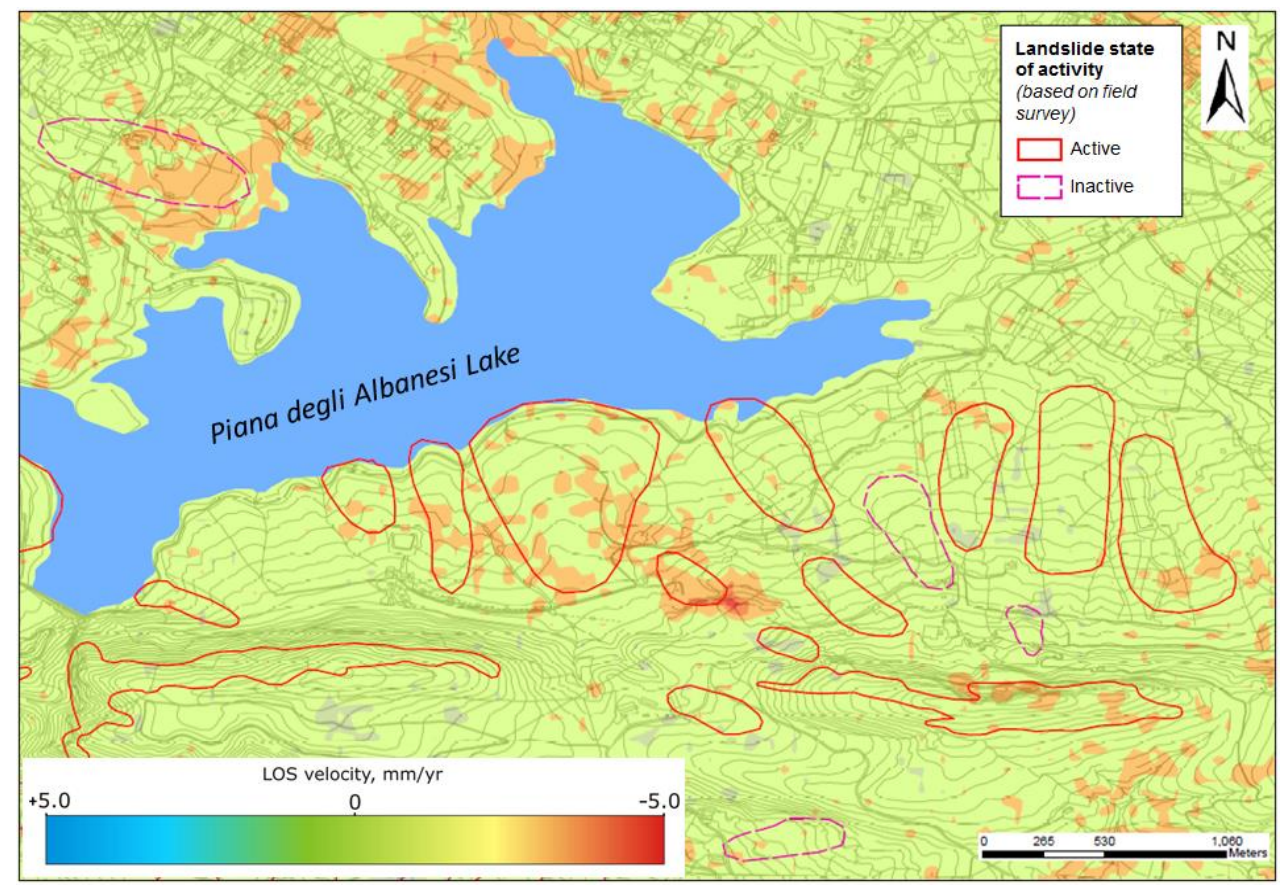

Figure 2: Interpolated ISBAS annual rates of ground motion in 2008-2011 for the area south of Piana degli Albanesi Lake, with indication of the boundaries of active and inactive landslides identified based on the field survey, overlapped onto 1:5,000 scale topographic maps distributed by the Regional Cartographic Center. 
COSMO-SkyMed ISBAS results reveal that during 2008-2011 slopes surrounding Piana degli Albanesi artificial lake to the south and east moved at LOS rates between -1.5 and $-5 \mathrm{~mm} /$ year (Figure 2), likely related to presence of structurally complex formations in the area of the Kumeta and Maganoce thrust fault.

Detailed information about very slow and extremely slow (according to the classification by ${ }^{26}$ ) landslide ground motion occurring in the investigated area confirms evidence and data gathered during field investigations, interpretation of aerial photographs carried out by the authors, and the pre-existing landslide inventory, and also complements the latter data sources by allowing improvement of landslide boundary delineation, even in some areas difficult to access. Predominance of complex and flow type landslides together with deep-seated gravitational slope deformations is found, the former linked to outcrops of marly and clayey lithologies and, the latter to the superposition of brittle carbonate over ductile rocks. Landslide mapping from field surveying is largely improved, by both redefining landslide boundaries, and identifying states of activity based on COSMO-SkyMed LOS rates for the years 2008-2011 and background information from the Italian Landslide inventory, the latter referenced to 2007, hence before the temporal coverage of the processed satellite data.

\section{CONCLUSIONS}

The outcomes of this work can be mainly discussed with regard to: (i) the performance of newly developed InSAR techniques across a region where only $2 \%$ of the land appeared suitable to generate radar scatterers based on pre-survey feasibility assessment; and (ii) the added value of both the processing technique and the high resolution data stack to the scope of updating the landslide inventory over Piana degli Albanesi in southern Italy.

The ISBAS test shows the improvement in the coverage of processing solutions that new InSAR techniques can provide for a variety of land covers, including non-urban and vegetated regions, where the likelihood of conventional approaches to identifying stable radar targets is very low. For the test area of Piana degli Albanesi, the low-pass ISBAS approach was employed to process two stacks of COSMO-SkyMed StripMap HIMAGE scenes, and allowed unprecedented coverage of ground motion monitoring results to be achieved, with an increase in this case of up to 40 times the conventional SBAS solutions. The combination of deformation estimates with field investigations, aerial photointerpretation and information from the pre-existing landslide inventory, resulted in an updated picture of landsliding processes affecting the region, including improved landslide delineation, assessment of state of activity and intensity. This study and its output will support the forthcoming generation of landslide susceptibility and risk maps at new levels of spatial detail and temporal updating that were not previously achievable in Italy and elsewhere.

\section{ACKNOWLEDGEMENTS}

This research was carried out in the framework of the cooperation between the University of Naples Federico II, the British Geological Survey (BGS) and the University of Nottingham (UoN), during the research visit of A. Novellino at BGS and UoN under the supervision of F. Cigna and A. Sowter. COSMO-SkyMed StripMap HIMAGE data stacks were made available to the University of Naples Federico II by the Italian Ministry for the Environment, Land and Sea. 1:5,000 scale topographic maps distributed by the Regional Cartographic Center. World Imagery available at: http://goto.arcgisonline.com/maps/World_Imagery. F. Cigna and C. Jordan publish with the permission of the Executive Director of the BGS, Natural Environment Research Council.

\section{REFERENCES}

[1] Rosen, P. A., Hensley, S., Joughin, I. R., Fuk, K. L., Madsen, S. N., Rodriguez, E. and Goldstein, R. M., "Synthetic aperture radar interferometry," Proceedings of the IEEE, 88(3), 333-382 (2000).

[2] Crosetto, M., Monserrat, O., Iglesias, R. and Crippa, B., "Persistent Scatterer Interferometry: Potential, Limits and Initial C- and X-band Comparison," Photogrammetric Engineering and Remote Sensing, 76(9), 1061-1069 (2010). 
[3] Berardino, P., Fornaro, G., Lanari, R. and Sansosti, E., "A new algorithm for surface deformation monitoring based on small baseline differential SAR interferograms," Geoscience and Remote Sensing, IEEE Transactions on, 40(11), 2375-2383 (2002).

[4] Ferretti, A., Prati, C. and Rocca, F., "Permanent scatterers in SAR interferometry," Geoscience and Remote Sensing, IEEE Transactions on, 39(1), 8-20 (2001).

[5] Werner, C., Wegmuller, U., Strozzi, T. and Wiesmann, A., "Interferometric point target analysis for deformation mapping." 2003 IEEE International Geoscience and Remote Sensing Symposium, IGARSS 2003 21-25 July 2003, 7, 4362-4364 (2003).

[6] Blanco, P., Mallorqui, J. J., Duque, S. and Navarrete, D., "Advances on DInSAR with ERS and ENVISAT Data using the Coherent Pixels Technique (CPT)." 2006 IEEE International Geoscience and Remote Sensing Symposium, IGARSS 2006, 31 July 2006 - 4 Aug. 2006, 1898-1901 (2006).

[7] Lanari, R., Mora, O., Manunta, M., Mallorqui, J. J., Berardino, P. and Sansosti, E., "A small-baseline approach for investigating deformations on full-resolution differential SAR interferograms," Geoscience and Remote Sensing, IEEE Transactions on, 42(7), 1377-1386 (2004).

[8] Bianchini, S., Cigna, F., Righini, G., Proietti, C. and Casagli, N., "Landslide HotSpot Mapping by means of Persistent Scatterer Interferometry," Environmental Earth Sciences, 67(4), 1155-1172 (2012).

[9] Bovenga, F., Wasowski, J., Nitti, D. O., Nutricato, R. and Chiaradia, M. T., "Using COSMO/SkyMed X-band and ENVISAT C-band SAR interferometry for landslides analysis," Remote Sensing of Environment, 119, 272-285 (2012).

[10] Cigna, F., Bianchini, S. and Casagli, N., "How to assess landslide activity and intensity with Persistent Scatterer Interferometry (PSI): The PSI-based matrix approach," Landslides, 10(3), 267-283 (2013).

[11] Colesanti, C. and Wasowski, J., "Investigating landslides with space-borne Synthetic Aperture Radar (SAR) interferometry," Engineering Geology, 88(3-4), 173-199 (2006).

[12] Herrera, G., Gutiérrez, F., García-Davalillo, J. C., Guerrero, J., Notti, D., Galve, J. P., Fernández-Merodo, J. A. and Cooksley, G., "Multi-sensor advanced DInSAR monitoring of very slow landslides: The Tena Valley case study (Central Spanish Pyrenees)," Remote Sensing of Environment, 128, 31-43 (2013).

[13] Strozzi, T., Ambrosi, C. and Raetzo, H., "Interpretation of Aerial Photographs and Satellite SAR Interferometry for the Inventory of Landslides," Remote Sensing, 5(5), 2554-2570 (2013).

[14] Meisina, C., Zucca, F., Notti, D., Colombo, A., Cucchi, A., Savio, G., Giannico, C. and Bianchi, M., "Geological Interpretation of PSInSAR Data at Regional Scale," Sensors, 8(11), 7469-7492 (2008).

[15] Wasowski, J. and Bovenga, F., "Investigating landslides and unstable slopes with satellite Multi Temporal Interferometry: Current issues and future perspectives," Engineering Geology, 174, 103-138 (2014).

[16] Calò, F., Calcaterra, D., Iodice, A., Parise, M. and Ramondini, M., "Assessing the activity of a large landslide in southern Italy by ground-monitoring and SAR interferometric techniques," International Journal of Remote Sensing, 33(11), 3512-3530 (2012).

[17] Cigna, F., Bateson, L. B., Jordan, C. J. and Dashwood, C., "Simulating SAR geometric distortions and predicting Persistent Scatterer densities for ERS-1/2 and ENVISAT C-band SAR and InSAR applications: Nationwide feasibility assessment to monitor the landmass of Great Britain with SAR imagery," Remote Sensing of Environment, 152, 441-466 (2014).

[18] Plank, S., Singer, J. and Thuro, K., "Assessment of number and distribution of persistent scatterers prior to radar acquisition using open access land cover and topographical data," ISPRS Journal of Photogrammetry and Remote Sensing, 85, 132-147 (2013).

[19] Tapete, D. and Cigna, F., "Rapid mapping and deformation analysis over cultural heritage and rural sites based on Persistent Scatterer Interferometry," International Journal of Geophysics, 2012, ID 618609, 1-19 (2012).

[20] Ferretti, A., Fumagalli, A., Novali, F., Prati, C., Rocca, F. and Rucci, A., "A New Algorithm for Processing Interferometric Data-Stacks: SqueeSAR," Geoscience and Remote Sensing, IEEE Transactions on, 49(9), 3460-3470 (2011).

[21] Sowter, A., Bateson, L., Strange, P., Ambrose, K. and Syafiudin, M., "DInSAR estimation of land motion using intermittent coherence with application to the South Derbyshire and Leicestershire coalfield," Remote Sensing Letters, 4(10), 979-987 (2013).

[22] Tapete, D., Fanti, R., Cecchi, R., Petrangeli, P. and Casagli, N., "Satellite radar interferometry for monitoring and early-stage warning of structural instability in archaeological sites," Journal of Geophysics and Engineering, 9(4), S10 (2012). 
[23] Bateson, L., Cigna, F., Boon, D. and Sowter, A., "The application of the Intermittent SBAS (ISBAS) InSAR method to the South Wales Coalfield, UK," International Journal of Applied Earth Observation and Geoinformation, (2014).

[24] Meisina, C., Notti, D., Zucca, F., Ceriani, M., Colombo, A., Poggi, F., Roccati, A. and Zaccone, A., [The Use of PSInSAR ${ }^{\text {TM }}$ and SqueeSAR ${ }^{\text {TM }}$ Techniques for Updating Landslide Inventories], In Margottini, C., Canuti, P. and Sassa, K.: "Landslide Science and Practice," Springer Berlin Heidelberg, 1, pp. 81-87 (2013).

[25] ISPRA, [IFFI, Inventario dei Fenomeni Franosi in Italia], (2007).

[26] Cruden, D. M. and Varnes, D. J., [Landslide types and processes], In Turner, A. K. and Shuster, R. L.: "Landslides: Investigation and Mitigation," Transportation Research Board, Special Report 247, pp. 36-75 (1996). 